\title{
Sheltering archaeological sites in Malta: lessons learnt
}

\author{
JoAnn Cassar $^{* *}{ }^{*}$, Shirley Cefai ${ }^{1}$, Reuben Grima ${ }^{1}$ and Katya Stroud ${ }^{2}$
}

\begin{abstract}
The purpose of this paper is to review the performance of the protective shelters installed over three archaeological sites in Malta over the past decade, and to draw some key lessons learnt that may be useful to others when considering whether to adopt a similar solution. The conservation threats to the Megalithic Temples of Malta are introduced and defined - these range from material issues (loss of surface) to structural issues (cracking and dislodgement of stones leading to structural instability and collapses). Causes identified specifically included fluctuating environmental conditions: wetting and drying cycles and thermal fluctuations, combined with the salt-laden Mediterranean island environment. The recognition during the late twentieth century of these issues as key factors in the deterioration of these structures, and the strategy that was developed in response, are outlined. A key component of this strategy was the installation of protective shelters over three of the main megalithic sites. The process through which the design requirements for the shelters were defined is reviewed. The performance of the shelters is then examined, through a critical review of unpublished reports and published studies. An evidence-based summary of the beneficial effects of the shelters is provided, and the possibility of any harmful effects discussed. A number of lessons learnt through this process are then identified. One key lesson is that the microenvironment in a newly-sheltered site is at a transitional stage that does not necessarily reflect longer-term trends, which therefore require long-term monitoring to be understood. The choice and number of environmental parameters to be monitored need to be informed by a careful consideration of their sustainability, both in terms of equipment and human resources. Any monitoring programme, however well-designed, needs to be open to re-evaluation and revision where needed. As more experience and data are accumulated from different sheltering projects, it will become more feasible to establish performance indicators in advance of a sheltering intervention, on the basis of which to evaluate its performance. The experience of these projects is then used to inform a checklist of key considerations for anyone considering whether to shelter an archaeological site. The foremost consideration is that every site requires a site-specific strategy tailored to its needs. The decision whether a shelter is desirable, and what its performance requirements should be, may only be taken in the context of such a strategy. This paper should help define the parameters for such a decision to take place.
\end{abstract}

Keywords: Megalithic Temples, Malta, Protective shelters, Condition assessment, Environmental monitoring, Weathering, Guiding principles

\section{Introduction}

The Megalithic Temples of Malta are inscribed on the UNESCO World Heritage List as a series of six prehistoric monumental complexes, built between the mid-4th and the mid-3rd millennium BC (Fig. 1). Originally, these structures are believed to have had a corbelled roof, and are considered to be the earliest stone buildings to achieve such a level of architectural sophistication, anywhere in the world. The Temples were constructed without mortar, with massive stones made of the local Globigerina and Coralline Limestones. ${ }^{1}$ The so-called

\footnotetext{
*Correspondence: joann.cassar@um.edu.mt

${ }^{1}$ Department of Conservation and Built Heritage, Faculty for the Built

Environment, University of Malta, Msida MSD2080, Malta

Full list of author information is available at the end of the article
}

1 The Globigerina Limestone is a softer, more porous, less durable stone.
The Coralline Limestone is harder, denser and more resistant to weathering. 


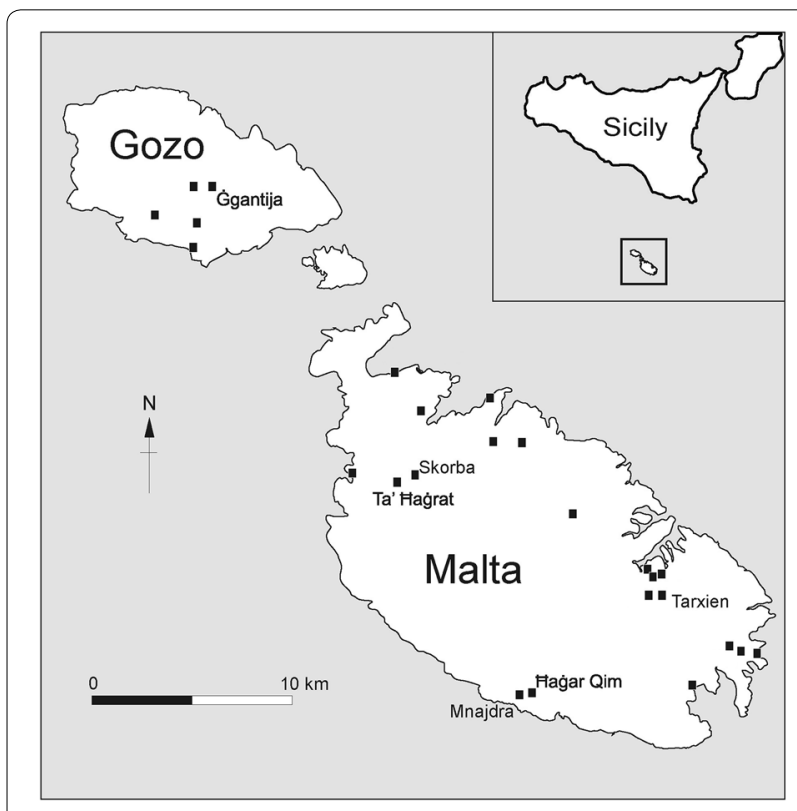

Fig. 1 Neolithic sites on the UNESCO World Heritage List located on map of the Maltese Islands

Temples consist of two separate walls, or "skins", which may be built either of Coralline Limestone or of Globigerina Limestone. Many elaborate sculptures inside the Temples are carved out of the soft Globigerina Limestone. Between the two walls is a rubble and soil infill. The present paper focuses on three of these megalithic complexes, namely Hagar Qim, Mnajdra and Tarxien (Fig. 2), ${ }^{2}$ over which a shelter (Fig. 3) has been installed during the past decade (Hagar Qim and Mnajdra in 2009 and Tarxien in 2015). Hagar Qim and Mnajdra have been exposed to the elements since their excavation in the early nineteenth century, while Tarxien was excavated and exposed to the elements in the early twentieth century. The upper parts of the Temples of Hagar Qim and probably even Mnajdra, were however always exposed (Fig. 4). The surrounding environment is aggressive as it is a marine environment laden with soluble salts. Anthropogenic sources of pollution, especially due to increasing traffic and also energy generation, are also very much present. $^{3}$ Other aggressive conditions, typical of the Mediterranean region, include very high temperatures in summer (up to $40{ }^{\circ} \mathrm{C}$ ) and very windy conditions [1].

\footnotetext{
${ }^{2}$ Hagar Qim and Mnajdra are located in a rural area, and close to the sea; Tarxien is in a more inland, urban environment.

3 Data on anthropogenic pollutants, including sulfur and nitrogen oxides are available at The Environment Report 2008, Sub-report 2-Air, Malta Environment and Planning Authority (MEPA), March 2010 available online at https://era.org.mt/en/Documents/The\%20Environment\%20Report\%20 2008.pdf.
}

Rainfall, though not excessive and limited to the autumn and winter months, often occurs in severe and continuous downpours which can last several days. This very often resulted in flooding of the roofless sites with the accumulation of large pools of water which could take many days to drain away, and the transport of much water downstream from the surrounding areas into the Temples-the case for Mnajdra and Tarxien in particular. The materials and mode of construction of the Temples, the absence of a roof, and the aggressive environmental conditions have led to a series of visible and cumulative problems over the years, including fissuring, loss of material at contact points between the megaliths and from the wall infill, and surface weathering especially of the porous Globigerina stones. These processes have in the past culminated in a number of serious collapses of both structurally important and minor parts of the structures, with the ongoing loss of the original integrity of the sites (Fig. 5). Hence, even relatively minor additional weathering of already weakened megaliths tends to lead to catastrophic collapses which were not often seen in the past.

On the basis of regular observations of these problems, a first project to study the condition of the Temples was initiated in 1985 and continued until 1991, as will be explained further on. This study included for the first time a thorough condition assessment of the sites (Hagar Qim and Tarxien were included in the project), from a structural and materials point of view, identifying structural issues and salt contamination as the major causes of the damage. This, in addition to the fast surface deterioration of the megaliths, and collapses in the 1990s, led to action being taken, which culminated in the sheltering of the Temples of Hagar Qim, Mnajdra and Tarxien. ${ }^{4}$

\section{Aim of this paper}

This paper reviews the sheltering of the Megalithic Temples of Malta as a process which can also help others in similar situations to decide on whether to shelter or not. Giving a synopsis of the problems faced by these sites over the decades, and their monitoring and documentation immediately preceding the decision to shelter the sites and in the longer term, it also outlines the multi-disciplinary team-work which was essential for the successful execution of the project. An early conclusion that the main causes of deterioration were the aggressive environmental conditions surrounding the sites, primarily

\footnotetext{
${ }^{4}$ The decision to shelter these sites was a long-drawn-out one-it was based on numerous meetings and long discussions by a multidisciplinary team of experts set up for the purpose by the Government of Malta in 2000. This particular decision was only one of a number of measures thought to be essential for the preservation of these sites in the long-term.
} 

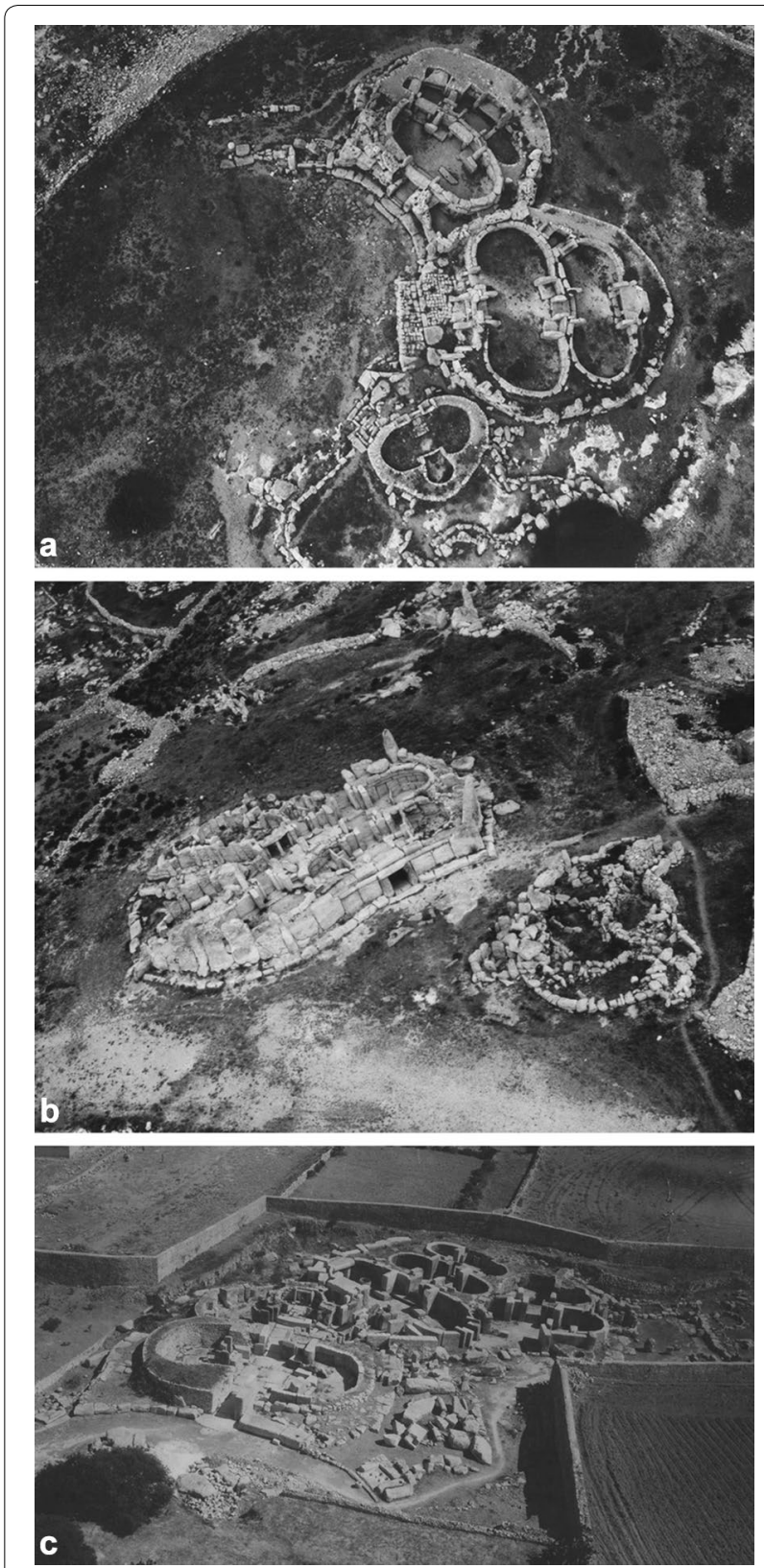

Fig. 2 Aerial views, prehistoric sites: 1950s a Mnajdra Temples, b Haġar Qim Temples, c Tarxien Temples

related to temperature, water and salts, and also anthropogenic pollution, led to extensive environmental monitoring, recording and documentation before and since the sheltering. An interpretation of the results of the monitoring in the light of the condition of the sites, before and after sheltering, is aimed at determining the effectiveness of the shelter, and also feed into the decision-making process on what to do next, which would inevitably have to be faced once the effective lifetime of the shelter ends. The Lessons Learnt from this project and assessment will lead to Guidelines being proposed to help other professionals who may be involved in the decision-making process whether to shelter other sites. ${ }^{5}$

\section{Issues concerning the stability and integrity of the Temple sites over the years}

In the late 1980s, awareness was growing in Malta and internationally that all was not well with the Temple sites. Regular site visits highlighted the fact that advanced powdering and flaking, as well as alveolar weathering of many of the Globigerina Limestone megaliths, and fissuring and formation of point-loads in load-bearing stones, were ongoing and were becoming serious concerns, culminating also in the destabilisation of both critical, and minor areas. It was also established that the sporadic interventions which until then had characterised attempts to preserve the sites were mostly futile; some, such as the pointing of fissures with cement, in themselves were accelerating the damage. Ponding inside the Temples was a regular occurrence over the years and loss of infill from the walls was practically continuous. Something needed to be done in a more holistic way. A multi-disciplinary joint project was set up between the Museums Department, ${ }^{6}$ Malta, and the University of Florence, Italy, to survey and assess the megalithic monuments, including Hagar Qim and Tarxien. This project, which included site work was carried out over a few weeks in the spring or autumn of every year, took place between 1985 and 1991 [2-4]. This included detailed site surveys and condition assessments, and the photogrammetric and manual documentation of structural damage, including fissures and displacement of megaliths. Studies of the construction materials were also carried out, and included chemical, mineralogical, petrographical and physical characterisation of the stones and any soluble salts present $[3,4]$. High concentrations of soluble salts were found in the Temple megaliths (up to $1.2 \%$ for chlorides in the Tarxien Temples) and high concentrations of sulfates (a maximum of $0.8 \%$ in samples from Tarxien) as well as high nitrate values (often over $200 \mathrm{ppm}$ and in one case reaching over $700 \mathrm{ppm}$ ) [5].

Further sampling and analyses carried out at Hagar Qim and Mnajdra by Mandrioli et al. (unpublished report $^{7}$ ) confirmed that these anions were not only still present, but were found in increasing quantities. Table 1

\footnotetext{
${ }^{5}$ Other considerations, including specific site considerations, are being addressed at a later stage.

6 The Museums Department was in charge of the Megalithic sites until the establishment of Heritage Malta

7 P. Mandrioli et al., Consiglio Nazionale delle Ricerche. Environmental Monitoring at Hagar Qim and Mnajdra Temples: Results and recommendations on the microenvironmental impact of the shelters for the Temples, 2006 (unpublished report).
} 


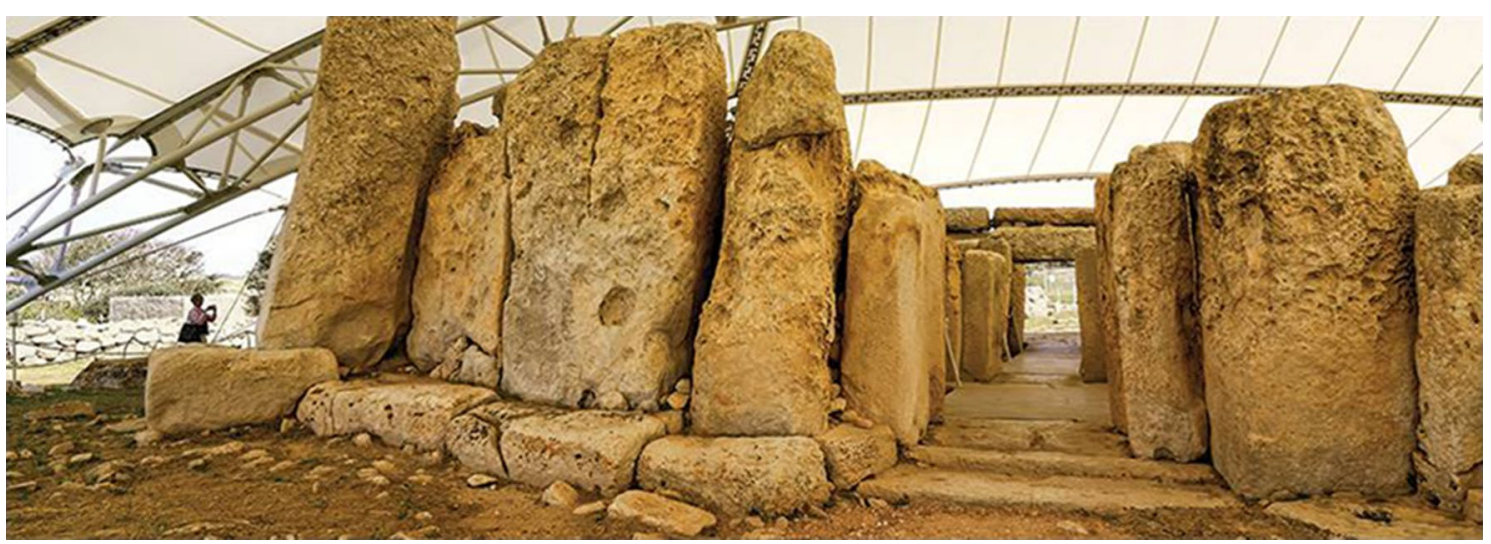

Fig. 3 The Haġar Qim Temples with shelter

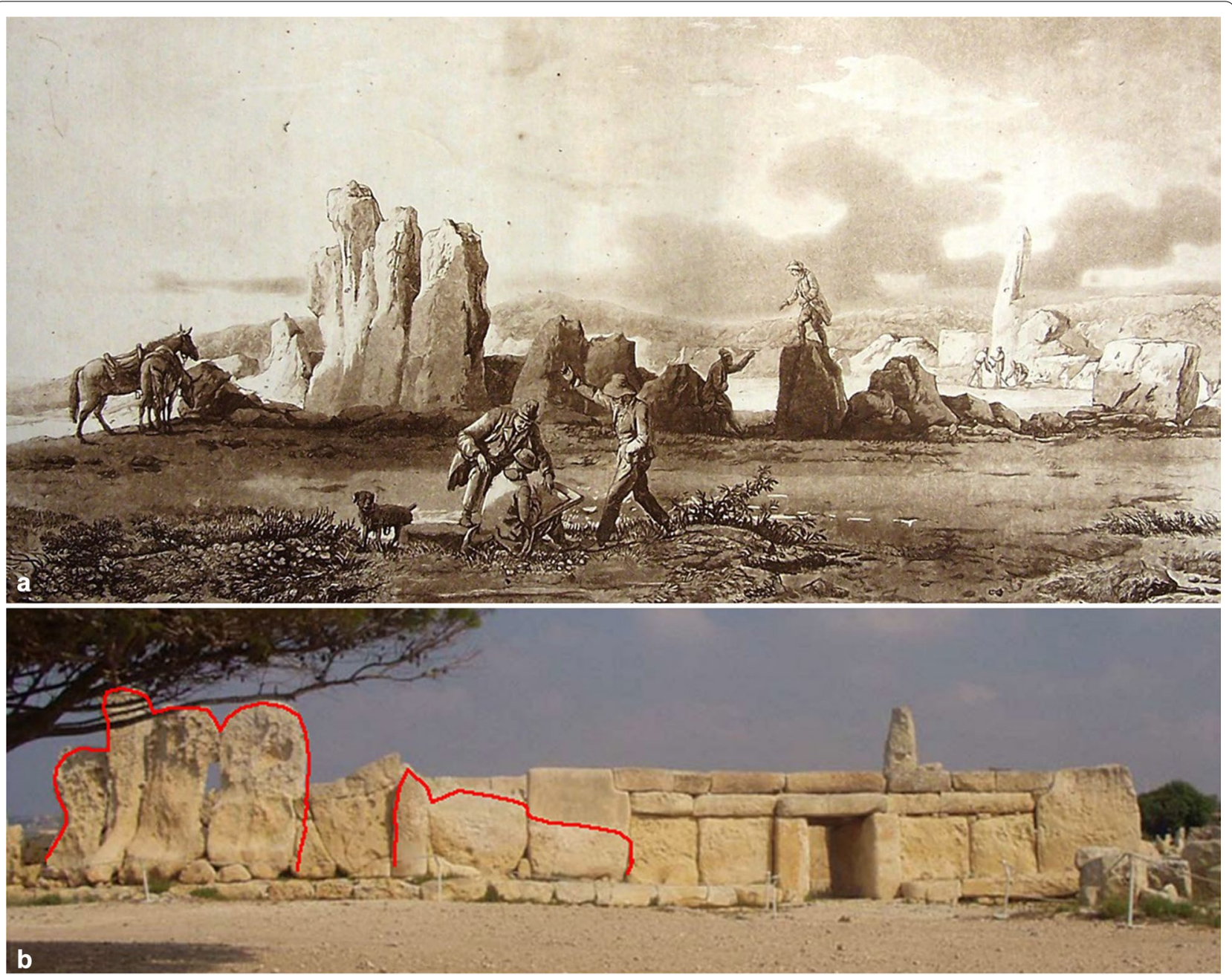

The red outline marks the megaliths that can be clearly identified in the print, showing that these were exposed prior to excavation.

Fig. 4 Façade of Haġar Qim: a 1787 print b photograph prior to shelter construction 


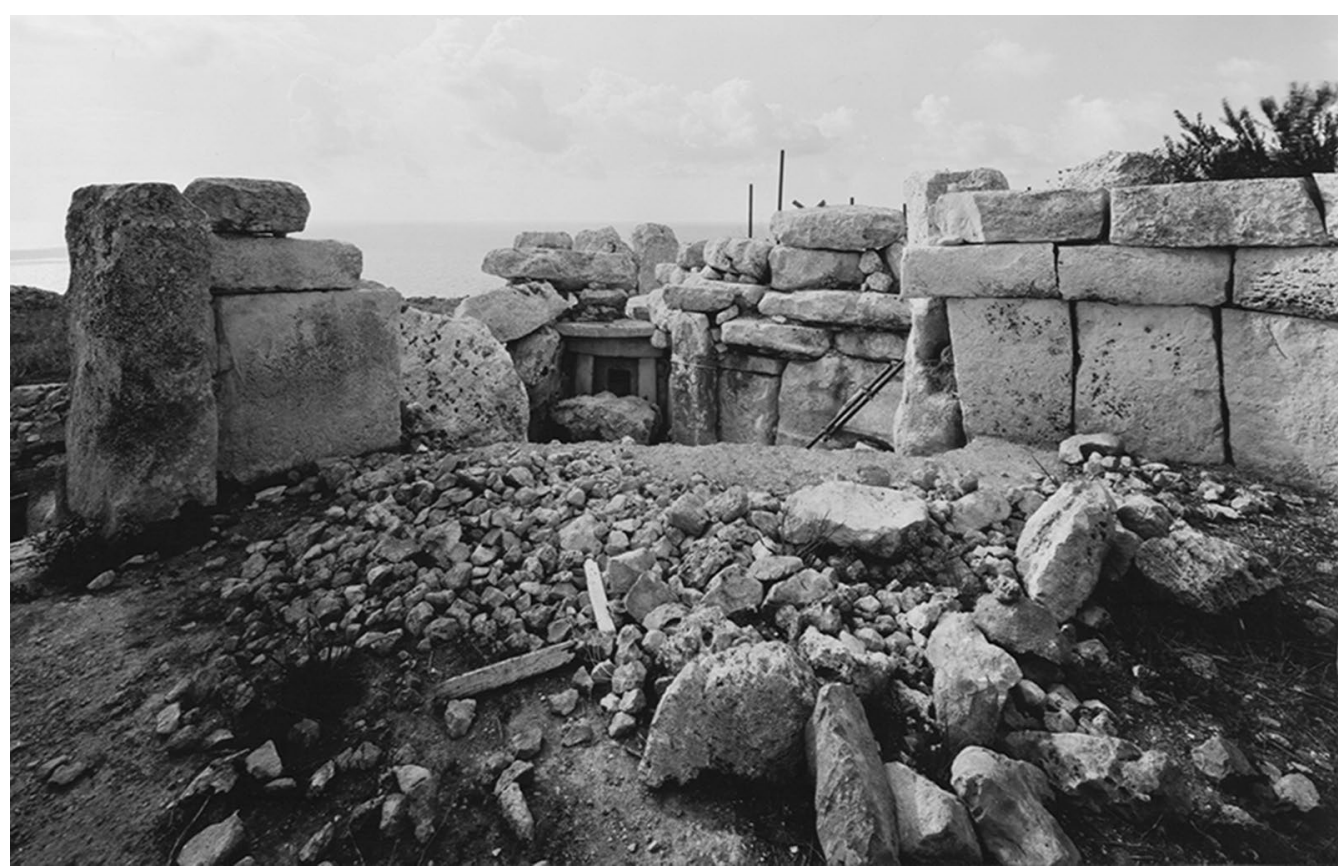

Fig. 5 Collapse of part of Mnajdra Temples, 1996, following heavy rainfalls with loss of structural stability

shows that for chlorides, sulfates and nitrates, significant increases on the megaliths were registered over two decades. The reasons for this great increase will be discussed at a later stage in this paper. XRD analyses gave the presence of halite at Hagar Qim and Tarxien [5]; XRD and SEM-EDX analyses confirmed the presence of halite, as well as gypsum in Hagar Qim, and halite and epsomite in Mnajdra (unpublished report: Mandrioli et al. (see footnote 7)).

Other studies carried out by Vannucci et al. [5] showed that the Total Open Porosity of weathered samples from Hagar Qim ranged between 18.7 and 45.5 and 30.6$52.15 \%$ for Tarxien, compared to the values of $38-41 \%$ obtained for fresh quarry samples. This confirmed that the stones were at times forming a less porous crust, and at other times were losing this crust to expose a badly deteriorated underlying substrate [6]. These results, taken together with the visual observations of serious powdering and flaking stone, and the verification and documentation of the widespread presence of fissures and unstable stones [3], which two processes were often found to be tightly linked, led to the conclusion that the sites were compromised and vulnerable to external impacts, and that the conservation problems of the sites could no longer be addressed by the piece-meal approach carried out until then. However, there was no easy solution in sight, and therefore nothing practical was done, except for the discontinuation of the use of cement for
Table 1 Anionic content in megaliths at Hagar Qim Temples

\begin{tabular}{llll}
\hline & Chlorides (ppm) & Sulfates (ppm) & Nitrates (ppm) \\
\hline Vannucci et al. [5] & $200-6293$ & $0-3238$ & $0-740$ \\
$\begin{array}{c}\text { Mandrioli et al. } \\
\text { (see footnote 7) }\end{array}$ & $1863-12,363$ & $1187-84,063$ & $252-8587$ \\
\hline
\end{tabular}

Sampling and analysis by Vannucci et al. took place from 1986 to 1989; Mandrioli et al. sampled in 2005. In both cases the number of samples analysed was 10 samples, from similar but not identical locations

repairs; visual monitoring and photographic recording continued, albeit sporadically.

However, there were to be other more immediate issues to contend with. In the 1990s the Megalithic Temple sites started to experience major collapses (Mnajdra in 1994; Hagar Qim in 1998) [7]. These serious issues brought home very clearly the realisation that something needed to be done in the short term to prevent the irreparable loss of these important sites, and to preserve their integrity.

A more detailed Condition Survey of the Temple sites carried out between 2005 and 2006 established the then existing situation and clearly identified specific conservation issues (Fig. 6). At the three Temple sites of Hagar Qim, Mnajdra and Tarxien, the loss of soil infill from between walls was recorded and clearly identified as a serious issue, exacerbated by the deterioration of the edges of the Globigerina megaliths which allowed more 


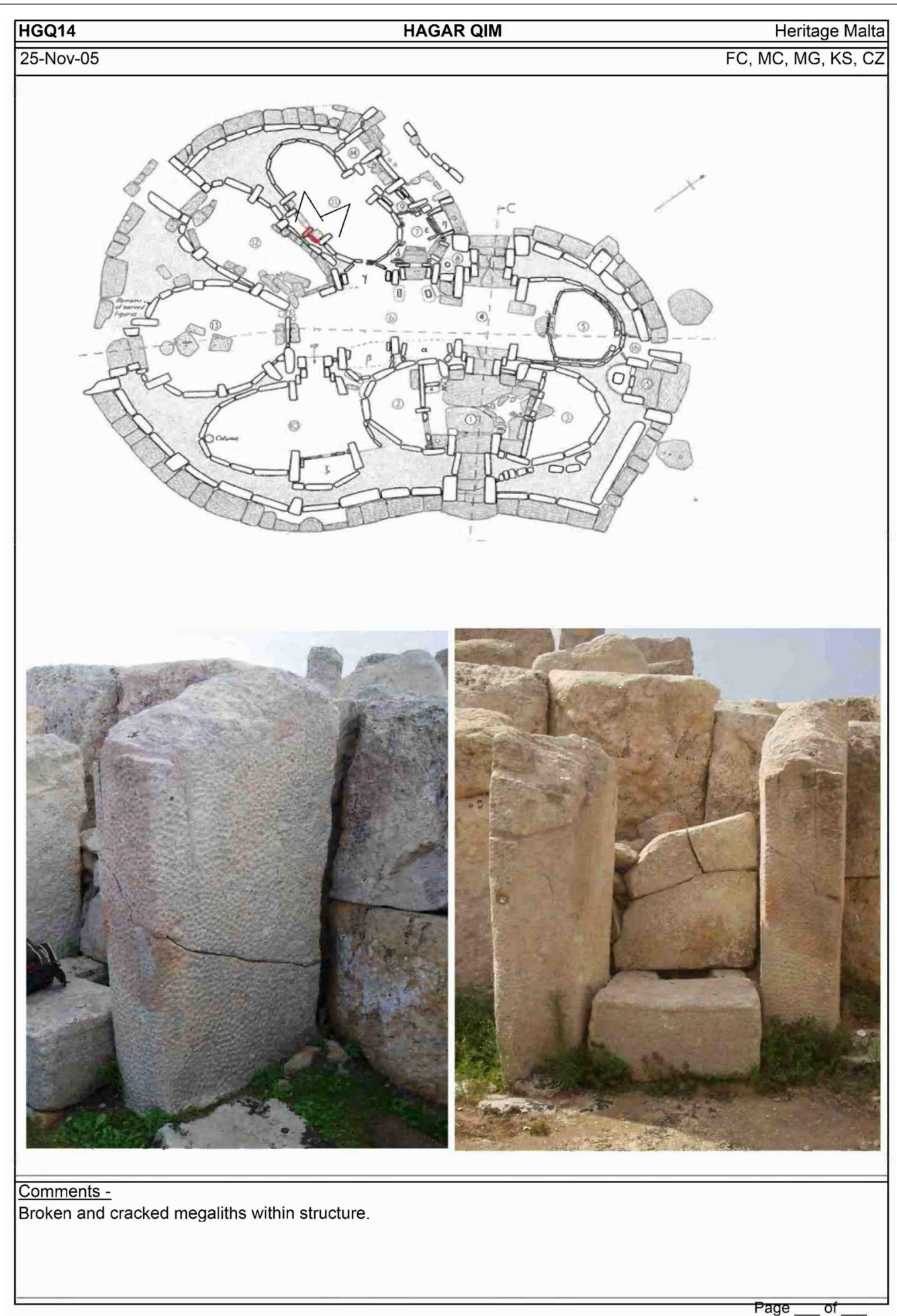

Fig. 6 Sample of Condition Assessment (2005-2006) record sheets 


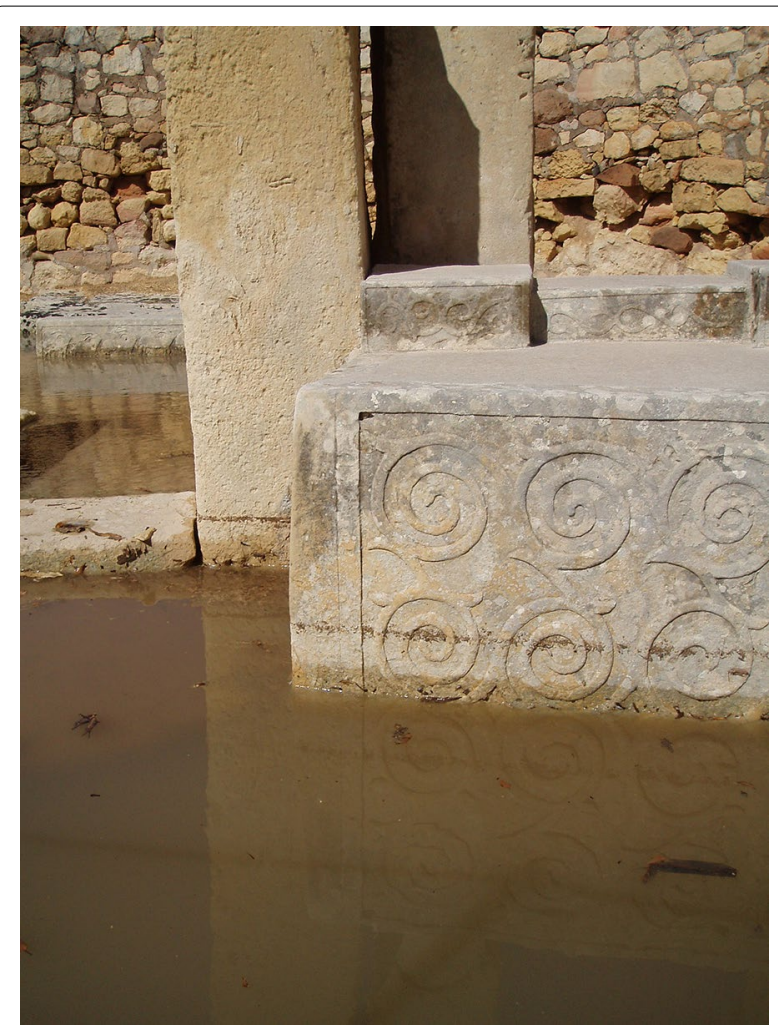

Fig. 7 Persistent flooding within the Tarxien Temples after heavy rains regularly reached $30 \mathrm{~cm}$ in depth

infill to leach out. The results were unstable walls and/or the creation of point-loads which in turn were leading to cracking of, and loss of material from, underlying megaliths. The rotation and collapse of some megaliths was also confirmed, putting other dependent structural elements at risk. A number of megaliths, some free-standing and others forming an integral part of a structure, were recorded to have breaks or cracks which were becoming worse with the accumulation of soil and the growth of vegetation (higher plants) in them. Surface loss, mainly seen as flaking and delamination was also found to be a concern, as already mentioned, often leading to sudden catastrophic collapses due to a loss of stability.

At Tarxien in particular, two other issues were evident; one was related to past conservation and restoration interventions (1956-1959) utilising large quantities of cement repairs and concrete capping, ${ }^{8}$ and another related to serious and regular flooding after heavy downpours, at times reaching a depth of $30 \mathrm{~cm}$ inside the Temple buildings (Fig. 7). Flooding was also an issue, though somewhat lesser, at Hagar Qim and Mnajdra. In all cases the accumulated water stagnated for days, and was also

\footnotetext{
${ }^{8}$ Iron dowels were also used, leading to stone cracking on rusting.
}

seen to be rising up the porous megaliths during the drying process.

A detailed biological survey ${ }^{9}$ was also carried out. This documented the presence of three communities of biological organisms on soils-a biotic crust, grass and vascular plants, with the greatest variety of vascular plants and the highest vegetation cover found in winter and spring.

On stone surfaces, the main biological communities identified were lichens, with a few vascular plants and mosses also recorded; a cryptogamic crust composed of lichens, algae, cyanobacteria and black fungi was also documented. Some of these were seen (in the already mentioned Condition Assessment) to be growing in cracks and fissures, widening them, whereas in the ground and infill root action was loosening previously compact material. Stone etching by lichens could also not be excluded.

\section{Sheltering of the sites: preliminary considerations}

A multi-disciplinary team ${ }^{10}$ set up by the Maltese Government in 2000 was to decide the way forward following the collapses. The first step was an evaluation of previous data and visual documentation on the Temples; it was concluded, after many brain-storming sessions, and also the study of case-studies in other countries [8], that environmental parameters were one of the main causes of the loss of material from the stones and infill, leading to structural problems, and eventually to the collapse of more vulnerable areas of the Temples. The main factors thus identified were: direct rain, direct insolation, salt, biological growth, and wind-related issues. Pollution was considered to be an issue for the Tarxien Temples, being located as already mentioned, in an urban area.

This then led to the conclusion that most of these issues could be tackled, at least in part, by sheltering the sitesfurther positive aspects included the fact that this could be considered a reversible, preventive measure that could be implemented in a relatively short space of time, yet provide literally umbrella protection for an entire site. It was thus determined that this should cut down on most of what had been at that point identified as the main causes of deterioration, and would also provide time to discuss whether alternatives (such as direct interventions

\footnotetext{
9 The methodology adopted for the biological surveys was that of identifying all organisms growing on soils, including soil on the floors as well as that on the top of the megalithic walls, and those growing on stone surfaces. These were documented by means of photography as well and by mapping of plant cover seasonally for each room and wall, determining the percentage cover for each species identified (unpublished report: A. Gómez-Bolea, Universitat de Barcelona, Environmental Monitoring at Hagar Qim and Mnajdra Temples: Final Report, 2008).

10 This was the Scientific Committee for the Conservation of the Megalithic Temples of Malta.
} 
Table 2 Different membrane materials tested at ISAC-CNR with results for light transmission and reflectance (unpublished report: Mandrioli et al. (see footnote 7))

\begin{tabular}{|c|c|c|c|}
\hline Material & $\begin{array}{l}\text { Surface } \\
\text { coating }\end{array}$ & $\begin{array}{l}\text { Light transmis- } \\
\text { sion } \%^{a}\end{array}$ & $\begin{array}{l}\text { Light reflection } \\
\%^{\mathrm{a}}\end{array}$ \\
\hline $\begin{array}{l}\text { Verseidag/Canob- } \\
\text { bio } \\
\text { Duraskin B18089 }\end{array}$ & PTFE & 12 & 60 \\
\hline $\begin{array}{l}\text { Ferrari } \\
\text { Flutop T2 } 1302\end{array}$ & PVC/PVDF & 10 & 70 \\
\hline $\begin{array}{l}\text { Verseidag } \\
\text { Duraskin B18059 }\end{array}$ & PTFE & 8 & 60 \\
\hline
\end{tabular}

${ }^{a}$ At $550 \mathrm{~nm}$

on the materials and structures themselves) could be a better option [9].

The proposal to erect a shelter naturally raised a number of concerns about the impacts of such an intervention, particularly those on the aesthetic and contextual values of the site [10]. In order to maximise reversibility, as well as to minimise the impact on the surroundings, it was decided to erect in each case an open, lightweight structure, ${ }^{11}$ where all attempts would be made to implement the principle of passive environmental control [9].

Once the shelter design was chosen, and proposals for the materials to be used in the construction of the shelters were being submitted to Heritage Malta, it was recognised that translucency and reflectance of the membrane would have a critical influence on conditions inside the shelters, and needed to be carefully chosen to minimise the risk of problematic issues such as a possible accumulation of heat in the hot summer months, or the instigation of biological growth. The results of the testing of various submitted materials are reproduced in Table 2 . The choice of material (polytetrafluoroethylene (PTFE) was chosen) was based on these findings as well as the tensile strength required for each individual shelter. As a result of the choice of material, the shelter at Mnajdra has a translucency of $8 \%$ and the one at Hagar Qim of $12 \%$, while both have a reflectance of $60 \%$. This chosen material was however known to have a life expectancy of 25 years, which made the evaluation of conditions at the Temples before and after sheltering even more vital in order to allow for informed decisions to take place when the lifetime of the membrane fabric had ended.

One year before the construction of the shelters at Hagar Qim and Mnajdra, and 4 years prior to the

\footnotetext{
${ }^{11}$ The chosen structures were designed and built as a pair of well-anchored trussed arches which shelter the main parts of each megalithic structure whilst maintaining the lowest possible height. Contextual and aesthetic considerations were also important issues, but are not the thrust of this paper, and are considered elsewhere $[9,10]$.
}

Table 3 A selection of air temperature and relative humidity data for the Hagar Qim Temples

\begin{tabular}{llllll}
\hline & \multicolumn{2}{l}{ Unsheltered } & & \multicolumn{2}{l}{ Sheltered } \\
& $\mathbf{T}^{\circ} \mathbf{C}$ & $\mathbf{R H} \%$ & & $\mathbf{T}^{\circ} \mathbf{C}$ & $\mathbf{R H} \%$ \\
\hline July 2014 & & & & \\
$\quad$ Average & 24.38 & 75.47 & & 25.56 & 72.47 \\
Max & 32.12 & 98.10 & 34.03 & 97.50 \\
Min & 20.51 & 28.70 & 20.72 & 28.10 \\
August 2014 & & & & \\
Average & 25.44 & 79.12 & 27.91 & 78.63 \\
Max & 33.73 & 99.80 & 35.84 & 98.20 \\
$\quad$ Min & 20.51 & 19.30 & 22.01 & 22.30 \\
September 2014 & & & & \\
$\quad$ Average & 25.20 & 80.04 & 26.10 & 78.83 \\
Max & 33.73 & 99.80 & 34.42 & 98.40 \\
Min & 20.51 & 19.30 & 20.72 & 22.40
\end{tabular}

Data are still being collected (as explained later, there are gaps in the multi-year record related to sensor breakdown in a very aggressive environment) at $15 \mathrm{~min}$ intervals inside and outside the shelters

implementation of the Tarxien shelter, comprehensive environmental monitoring commenced, based on the environmental factors already identified as having a crucial role in the deterioration of the Temples. This was aimed at setting up a base-line which would allow for the establishment of pre-sheltering conditions, to allow for the necessary evaluation of conditions inside the shelter after its construction, and also permit the determination and quantification of any changes occurring post-sheltering, as well as the assessment of their effects; data are still being collected today. ${ }^{12}$ The exact type of monitoring to be carried out was influenced by the fact that Hagar Qim and Mnajdra are located in a rural setting close to the sea, whereas Tarxien is located in an urban setting, surrounded on practically all sides by buildings; however the basic parameters monitored are the same. Environmental monitoring equipment thus includes a weather station to monitor relative humidity, air temperature, solar radiation, rainfall, wind speed and direction and barometric pressure. Table 3 gives a selection of comparative data for air temperature and relative humidity for the summer of 2014, in sheltered and unsheltered areas of the Hagar Qim Temples, which data represent part of the data set then used to evaluate the effectiveness of the shelters in

\footnotetext{
${ }^{12}$ A serious limitation when monitoring in aggressive environments, is the breakdown of sensors, usually due to the accumulation of dust and salts on them, with ensuing corrosion and a break in the monitoring. These have led to frequent and often large gaps in the data, and are also a serious running expense not always recognised at the outset. Consequently, a long run (ca 1 year) of uninterrupted data collection was not often verified. This necessarily made data evaluation more complicated than envisaged (see also [8, 14]).
} 
relation to salt damage. In addition, inside the Temples, soil moisture, stone surface temperature and stone surface wetness were monitored. Pollution monitoring is also being carried out at Tarxien, ${ }^{13}$ whereas soil erosion and water accumulation were measured at Mnajdra pre-sheltering.

Short complementary environmental campaigns carried out pre-sheltering included sampling and analyses of biological aerosol and atmospheric aerosol, thermal infrared imaging and measurements, sampling and analyses of stone surfaces, biological mapping and the recording of wind turbulence in a number of chambers. These are being repeated at intervals (depending on resources) even after the sheltering (see also below).

The parameters to be monitored, as explained above, were chosen on the basis of perceived environmental effects on the Temple sites, as well as those factors which it was decided could help understand the performance of the shelters, both in the short and long term.

The issues to be addressed by the chosen design, and selected membrane, and which would later be taken up during the evaluation process, were:

1. Direct rain-related issues such as infill loss, leaching and ponding inside the sites, by an umbrella-effectto be evaluated by direct observation, photographic documentation and repeated condition assessments.

2. Indirect rain-related issues including the weakening of stone structure (by loss of infill and stone loss of stone surface material) and the activation of salt weathering-only to be partially evaluated by direct observation, photographic documentation and repeated condition assessments; activation of salt weathering was to be determined indirectly through environmental parameters.

3. Direct insolation (providing shading) which could address thermoclastism - to be determined by surface temperatures recorded directly and by thermal imaging.

4. Indirect reduction of biological growth, affecting primarily the infill and ground (by shading and decreasing water supply) reducing root damage and surface etching-to be determined by repeated biological surveys.

5. Indirect wind-related issues such as abrasion and wind-induced drying, wind-borne aerosols, both biological and inorganic - to be determined indirectly by measuring wind parameters post-sheltering.

\footnotetext{
${ }^{13}$ Tarxien being situated in an urban area, quite close to the energy generating power station, pollution was also here considered to be a potential issue.
}

How these variables were evaluated, and conclusions drawn, will be discussed further on.

However, it was also recognised from the outset that a shelter would not in any way mitigate against anthropogenic factors or environmental disasters such as earthquakes, floods or whirlwinds, and which were above and beyond the environmental issues which could be addressed by a shelter. Existing stone material and structural issues would also not be addressed.

\section{Documentation and monitoring}

A 3D digital model of the sites ${ }^{14}$ was commissioned before the shelters were erected, in every case. This was achieved by laser scanning and photographing the sites to produce a three-dimensional geo-referenced digital model of the prehistoric buildings as well as the terrain around them (in the case of Hagar Qim and Mnajdra). The aim was that yearly condition assessment records (see below) as well as historical records would be overlain on these models to follow and determine changes preand post-sheltering. ${ }^{15}$

A Condition Assessment of all the stones of all the Megalithic Temples, including Hagar Qim, Mnajdra and Tarxien, was conducted in 2005-2006, consisting of the methodical visual inspection and documentation of structural issues and material deterioration at each site. This had a twofold aim: to be able to compare with postsheltering condition assessments (currently again under way) and to aid in developing methodologies to tackle particular categories of problems (all issues were divided into related categories e.g. structural; infill, ground; surface weathering) and therefore facilitate targeted conservation interventions, for issues (already mentioned) which the shelter itself would not address.

Following the observations made with regards to flooding at the Tarxien Temples in the event of heavy rainfall, a hydrological and hydrogeological study was commissioned ${ }^{16}$ also to inform on the correct disposal of rainwater from the large shelter to cover the site, the Temple being situated in an urban area far from the sea (unpublished report: P. B. Grech ${ }^{17}$ ).

\footnotetext{
${ }^{14}$ In 2005, ABC General Engineering was contracted by Heritage Malta through the European Regional Development Fund for 2004-2006 Structural Funds, to produce high-definition 3D documentation of Hagar Qim and Mnajdra Temples. In 2011, DMT Group was contracted by Heritage Malta through the European Regional Development Fund for 2007-2013 Cohesion Policy, to produce high-definition 3D documentation of Tarxien Temples.

${ }^{15}$ Issues with the manipulation of these very large files still persist.

16 This was carried out by a Water and Waste Water Engineer in 2010.

17 PB Grech. Hydrological and Hydrogeological Studies at the Tarxien Temples (Malta). Final report 2011 (unpublished report).
} 
A survey of biological organisms growing on soils and stone surfaces at Hagar Qim and Mnajdra was carried out over a period of 1 year ${ }^{18}$ with seasonal campaigns taking place between November 2007 and August 2008. For Tarxien this was carried out over a period of 1 year ${ }^{19}$ between 2011 and 2012. These have now been repeated in all cases, as will be discussed further on.

\section{Limitations of selected methodologies}

The environmental monitoring methods chosen had of course their limitations. Whereas for some parameters, it was possible to set up automatic continuous monitoring (the parameters covered by the weather station, as well as surface temperature and surface wetness of the stones and soil moisture) other parameters by their very nature could only be addressed periodically-these included aerosol sampling (and analyses), pollution monitoring (at Tarxien), thermal imaging and air turbulence measurements. In the case of the continuous monitoring, the equipment here was plagued with repeated breakdowns of the sensors-and hence loss of essential data-in what is essentially a very aggressive marine environment. This resulted in loss of data, gaps in the monitoring results, some loss of calibration and a regular-and not insignificant-expense. Discontinuous monitoring, and here the surveys and condition assessments can also be included, on the other hand, was labour-intensive and involved the necessary deployment of often scarce human resources for days at a time. As a result, the datasets collected over the years, though substantial, were occasionally found lacking in certain respects, and more data could have led to more accurate conclusions. This shortcoming is also related to the decision, which needed to be necessarily taken a priori, of the areas to be monitored and the frequency of monitoring. There was no prior casestudy where such extensive monitoring, for such a long period of time, had been undertaken before sheltering of a site, and hence all these variables had to be freshly established. And this leads to a familiar dilemma: more monitoring is more expensive, and is also associated with the risk that "too much data" can either be unwieldy to manage, or else be too time-consuming to evaluate comprehensively; less monitoring on the other hand, can lead to serious gaps in the datasets which can make the other available data very difficult to interpret, or even lead to false conclusions if the data are inadequate. In addition,

\footnotetext{
${ }^{18}$ This was carried out by experts from the Universitat de Barcelona (Unpublished report: A. Gómez-Bolea et al., Universitat de Barcelona, Environmental Monitoring at Hagar Qim and Mnajdra Temples: Final Report, 2008).

19 This was also carried out by the Universitat de Barcelona (Unpublished report: A. Gómez-Bolea et al., Universitat de Barcelona, A Study of Biological Communities at Tarxien Temples, Final Report, 2012).
}

if one or more of the areas chosen to be monitored are inappropriate-i.e. if they are less than optimal in relation to the question posed upstream-data interpretation and evaluation can be compromised. The consequences of these limitations will be further discussed below.

\section{Evaluation of performance Positive impacts}

Visual site inspections, comparison of the present situation with pre-sheltering photographic and other records, including the condition assessment and biological survey, as well as the evaluation of environmental monitoring data for all three sites ${ }^{20}$ have shown that the main waterand insolation-related issues have been immediately and directly mitigated [8]. A well-designed shelter, albeit open-sided, based on previously established criteria, and an efficient guttering system have resulted in direct rainfall, and most of the wind-driven rain, being mostly eliminated, with no flooding and ponding occurring post-sheltering in any of the three sites. The ground, megaliths and infill are not affected by direct water penetration. The infill loss has slowed down and no further collapses have been recorded. A more thorough repeat of the pre-sheltering Condition Assessment is being planned to formally document, again on a stone-by-stone basis, any visual changes that have taken place since the sheltering, and to then digitally compare the before and after information-as already mentioned there are issues with using directly the 3-D models available. ${ }^{21}$

Transport downstream of rainwater at Mnajdra however still occurs, although most of this does not directly reach the inside of the Temples-if any residual rainwater does so, this needs to be evaluated with the deployment of additional soil moisture sensors. In addition, the possible contribution to ground water of rainwater falling outside the shelter, which can indirectly affect the megaliths, needs also to be evaluated. The overall situation is however that of a perceived increased surface dryness on the stones, ground and infill.

Wind measurements for Hagar Qim have also shown no negative effects post-sheltering. In fact, wind has been found to decrease in velocity under the shelter, ${ }^{22}$ and to increase again on leaving [11]. In addition, a very slight

\footnotetext{
${ }^{20}$ It is to be noted that for Hagar Qim, more studies were carried out than for Mnajdra than Tarxien - as it was considered to be one of the most compromised sites as well as for the fact that it is composed entirely of Globigerina Limestone in a very exposed situation $[3,5]$.

${ }^{21}$ With hindsight, the models commissioned could have been less detailed, but more easily manipulated, to facilitate the overlaying of data collected from the various surveys.

${ }^{22}$ Post-sheltering wind speed (and turbulence) monitoring inside and outside the Hagar Qim shelter was carried out in 25 different locations and in four directions, from November 2009 to March 2010 [11].
} 
Table 4 Temperatures recorded on Hagar Qim megaliths, with and without shelters (approximate values from thermal imaging)

\begin{tabular}{lllll}
\hline Date & Time & Shelter/no shelter & Surface temperature recorded & Comments \\
\hline 29 June 2005 & $9.30 \mathrm{am}$ & No shelter & Up to $40{ }^{\circ} \mathrm{C}$ & Very uneven heating \\
13 June 2012 & $9.27 \mathrm{am}$ & Sheltered & Ca $25{ }^{\circ} \mathrm{C}$ & More even heating; air temperature $25^{\circ} \mathrm{C}$ \\
13 June 2012 & $9.21 \mathrm{am}$ & Unsheltered area & Up to $37{ }^{\circ} \mathrm{C}$ & ${ }^{\circ} \mathrm{C}$ difference between two differently exposed areas \\
\hline
\end{tabular}

increase in wind speed has been registered mainly when south-easterly winds blow through the main trilithon entrance to the site, which faces this direction. This certainly put to rest any concerns that the shelter may have increased wind velocity and/or turbulence underneath it. The possibility of vortices and currents around specific megaliths, caused by the morphology of the ruins, has not been verified, although the identified susceptible areas around the entrance are being carefully monitored.

The direct effects of solar radiation on stone surfaces have been reduced dramatically. Stone surface thermal imaging was carried out on two comparable occasions both pre-sheltering and post-sheltering, at both Hagar Qim and Mnajdra ${ }^{23}$ Data (approximate) obtained from the images thus obtained ${ }^{24}$ (Table 4) show a great decrease in thermal gain on the surface of the megaliths studied.

Thus a significant "shading" effect has been noticed, measured and recorded. This is certainly addressing one of the main causes of deterioration which has been identified for the stone megaliths of Malta, and carbonate stones in the Mediterranean Basin in general-thermoclastism (thermal stress) $[8,12]$.

Direct surface temperature measurements, on the other hand, found that for south- and west-facing megaliths, maxima have decreased, but have increased in north-facing ones, smoothing out previous differences between the different orientations [8]. Minima on southfacing megaliths have also increased ${ }^{25}$ (Table 5). This is understood as being the effect of a reduction in direct solar radiation together with a decrease in the cooling which usually occurs during the night, a decrease caused by the presence of the shelter, as determined by Becherini

\footnotetext{
${ }^{23}$ From P. Mandrioli et al. 2005 Environmental Monitoring at Hagar Qim and Mnajdra Temples July 2005 - June 2006: Unpublished Interim Report, and by Mario Galea, Heritage Malta, between July 2005 and June 2006.

24 Thermal imaging can only be captured in a discontinuous manner; in this case it was carried out in periodic visits, during which the thermal camera needed to be mounted and manned on site within the area normally accessible to visitors.

25 The data distribution of these values is not normal. The Wilcoxon Test reveals that in all four cases the differences are considered to be statistically significant.
}

Table 5 Direct surface temperature measurements, preand post-sheltering at Hagar Qim; south-facing megaliths

\begin{tabular}{llrrr}
\hline & $\begin{array}{l}\text { Surface } \\
\text { temperature }\end{array}$ & No shelter $\left({ }^{\circ} \mathbf{C}\right)$ & With shelter $\left({ }^{\circ} \mathbf{C}\right)$ & $\boldsymbol{\Delta}\left({ }^{\circ} \mathbf{C}\right)$ \\
\hline August & Max & 39.1 & 34.7 & -4.4 \\
& Min & 19.6 & 21.3 & 1.7 \\
& Average & 26.0 & 26.6 & 0.6 \\
January & Max & 26.1 & 18.4 & -7.7 \\
& Min & 2.8 & 3.2 & 0.4 \\
& Average & 10.6 & 12.8 & 2.2 \\
\hline
\end{tabular}

After Becherini et al. [8]

et al. [8]. Further thermal imaging is planned to continue to investigate these differences.

Microclimatic (air temperature and relative humidity) monitoring provides most data for the sheltered and unsheltered Temples, and hence is a key focus of any evaluation of the changes brought about by the shelters. ${ }^{26}$ The conclusions drawn in a recently published paper [8] are that environmental conditions beneath the shelters have generally improved, with no noteworthy dissimilarities between the two Temples of Hagar Qim and Mnajdra being observed. Fluctuations in air temperature and relative humidity under the shelters have been found to be for the most part dampened. As these are the parameters which directly affect salt crystallization cycles, and hence a primary cause of stone damage in this marine environment, ${ }^{27}$ mitigation of such fluctuations can therefore be considered a positive aspect of the project, and will be discussed further on in relation to salt weathering. This also in the light of the fact that over a 20 year period (1985-2005) as already seen, there was a very large increase in the concentration of soluble salts on the surface of the megaliths, which can be attributed to a cumulative effect related to aerosol deposition and also rising damp (associated also with extreme ponding events already mentioned) and ensuing surface drying. This also

\footnotetext{
${ }^{26}$ This is also due to the fact that cyclical damage, such as that brought about by the presence of soluble salts, is instigated by changing environmental conditions.

27 The limestone megaliths are porous and hence greatly prone to salt damage.
} 
negates the long-held but unverified idea that rainfall simply "washes out" the salts from the megaliths-a discussion also take up at a later stage in this paper.

Another study [13], concentrating on the Temple of Hagar Qim, has shown that air temperatures outside fluctuate more than in the centre and on the periphery of the shelter, showing externally higher maximum temperatures in summer and lower ones in winter. The maximum differences were in fact noted between inside and outside during the hottest months. It is therefore concluded that the shelter keeps the air temperatures in the centre of the shelter more stable.

The relative humidity levels recorded beneath the shelters were on the other hand not very different from those registered outside, and were generally still high at around $80 \% \mathrm{RH}$. Saturated conditions were noted frequently under the shelters, with some increased risk for condensation, especially seen on the shelter membrane and metallic trusses supporting it [8]. This has so far been attributed, at least in part, to the slow drying of the ground, infill and megaliths (note also observation on "greening" below) and which is being monitored to detect without delay any possible negative impacts [8].

Higher plants, which in the past often grew on the soil infill, and in cracks and fissures as mentioned previously, aggravating an already existing structural problem in megaliths so compromised, have now been eliminated. A decrease in light levels, and a lack of available moisture, has addressed this issue.

The lichen communities on the megaliths, on the other hand, are more resilient, and any changes that may happen are expected to be longer term. After four years of sheltering, changes in "the lichen composition of major community types were insignificant" (unpublished report: Sammut S., 2013, p. 18). ${ }^{28}$ As however an associated reduction in the abundance and cover afforded by some of the lichen species has been noted, it could be said that some initial effects were being felt, and continued monitoring is occurring.

An unintended benefit of the shelters was detected after some informal visitor surveys elicited comments that the shading and sheltering (from rain) has increased visitor comfort, while the diffused light provided by the shelters improves the legibility of the site, resulting in an enhanced visitor experience [10].

\section{Ongoing evaluation}

Becherini et al. [8] in their paper evaluating the environmental effects of the shelters at Hagar Qim and Mnajdra, concluded that the shelters have slightly decreased the risk caused by the crystallization cycles of halite and epsomite (two of the salts present in the megaliths), at least individually. This inference, combined with the probability that the stones are going through fewer wetting and drying cycles (also because of less ponding at the foot of the megaliths) is likely to lead to less stone damage by soluble salts. This however excludes the effects of possible condensation events (mentioned above). Cabello-Briones and Viles [14] on the other hand concluded from their study for Hagar Qim, that there were "fewer $\mathrm{NaCl}$ crystallization events outside the shelter than in the centre" (p. 7). It is to be noted that the studies of Cabello-Briones and Viles took place over one year in 2013-2014, whereas the period taken into consideration by Becherini et al. was 2014-2015-this can lead one to conclude that there is a variation from 1 year to another inside the shelters (they are open-sided shelters which do react to their environment). Another conclusion could be that the situation did improve from 1 year to the next, and this needs to continue to be carefully monitored. In addition, Cabello-Briones and Viles [14] also mention, quoting Becherini et al. [8] that these results must be evaluated cautiously, as the RH sensors are very susceptible to moisture and dust accumulation and therefore the accuracy can be compromised - this has already been mentioned above as one limitation of the study. A difference detected by Cabello-Briones and Viles between the centre and the border of the site, with the air temperature in the peripheral area being higher than the centre in winter, also needs to be monitored. They also mention "direct solar radiation on the ruins towards the edge" (p. 698). The general conclusion was however here too that overall, "the risk of salt weathering inside the shelter is lower inside than outside because the microclimate is more stable", p. 701.

In addition, the fact that ponding inside the Temples ${ }^{29}$ has been eliminated, with a reduction in the ensuing process of rising damp carrying salts [15] into the porous megaliths and activating ones already present, and that the $\mathrm{RH}$ inside the shelter is now more stable (around $80 \%$ ) can mean that the shelter has in fact had an overall positive, if indirect effect, on salt weathering, but this important facet is far from being resolved, and needs further research.

A visible sign that moisture movement and drying out of the stones were occurring in the very early stages after sheltering was an unexpected very short-term visual observation of the "greening" of a few megaliths

\footnotetext{
${ }^{28}$ S. Sammut, Biological Survey at Hagar Qim and Mnajdra, 2013 (unpublished report)
}

${ }^{29}$ This is the case for all three sheltered sites, but primarily for Tarxien and Mnajdra where the problem was most serious, as already stated. 
inside the Mnajdra complex shortly after the erection of the shelter. This can possibly be attributed to biological growth. The effect lasted only a few weeks and was not seen anywhere else in the sheltered Temples either then or at any point after that. Monitoring will continue to detect any recurrences.

Lichens, as has been mentioned, occur on many of the megaliths in the three Temple sites being studied. These organisms can cause biodeterioration of stone, including limestone [16] but this is a much slower process than that caused by other physical and chemical agents, in which case they in fact can play a "protective role" which could change post-sheltering, a possible negative side-effect, not to be underestimated [17]. As has already been mentioned however, as physical and chemical impacts lessen, this "protective" effect could become less important. There is also the consideration that lichen hyphae can penetrate into both natural rocks and building stones, and can thus add to physical weathering processes as well as mechanical damage and can also accelerate other forms of physical weathering [16]. So a decrease in lichen cover could, from this point of view, be beneficial.

The biological survey also found that different types of lichens preferred different orientations as well as different levels of exposure to the environment. These are being regularly monitored due to the possible direct effect on the stone surfaces (mentioned above) and the possibility that if lichen communities change, this could also have a visible effect. This has not been verified to date.

\section{Negative impacts}

There is a possible loosening of soil particles due to the drying out of soil in horizontal areas, where a significant decrease in biological growth (mainly higher plants) has been registered (at Hagar Qim and Mnajdra); these are the areas which in the unsheltered situation received most light and rain. The unbound soil particles can then be deposited and accumulated inside the sheltered zones. It has in fact been observed that dust deposition has increased, particularly on horizontal surfaces, by Cabello-Briones and Viles [13], and by Galea et al. on their vertical aerosol samples [18].

In their study on the Hagar Qim Temples, CabelloBriones and Viles [13] noted that there was more dust deposition on horizontal surfaces inside than outside the shelter, commenting also that windblown dust from the arid surroundings could enter under the shelter driven by wind and accumulate when wind reduces velocity, as mentioned previously [11] - this in addition to any effects of the loss of biological crusts.

It has in fact been recently observed by the authors that a reddish hue, which can be attributed to dust accumulation, does affect the megaliths of Hagar Qim and
Mnajdra, though (as yet) not those of Tarxien; as already mentioned, Tarxien is situated in an urban environment, rather than the countryside. Dust deposition at Hagar Qim has also been examined and reported in a published pilot study on pollution monitoring [18]. In this study, three separate short (approximately 2 weeks each) sampling campaigns ${ }^{30}$ were carried out, where in each chosen location three passive aerosol samplers were placed at a very low height (less than $0.5 \mathrm{~m}$ above the ground), with different orientations; and aerosol deposits were collected on Nuclepore $^{\mathrm{TM}}$ filters and then analysed. The actual type of filter is not given and hence the actual particle sizes of the dusts collected in not known. In fact, Camuffo [19] states that "deposition mechanisms vary with the particle diameter, surface characteristics, microclimate and air surface interactions.... The knowledge of the chemical and physical characteristics of individual particles, their relative abundance in the atmosphere and the deposition mechanisms that favour their transport and selective deposition should lead to a profound review of the dynamics of chemical aggression and should also clarify ideas about what can or cannot be done to reduce the negative effects of pollutants." (p. 324). This must be taken into consideration when discussing the results obtained, and conclusions drawn. In addition, any data gathered here can only relate, indirectly, to what happens at this very limited height above the ground, and can only apply to the particle sizes actually sampled.

In fact, one of the conclusions drawn by Galea et al. is that their campaign results "point to trends of greater pollutant accumulation, particularly dust" "directly linked to the intrinsic shape of the temple interior, as well as to the micro-environmental factors that are changing as a direct result to the sheltering" (p. 324). Specific mention is made of the phosphate concentrations of the ions analysed in the third (sheltered) campaign. On the other hand, another comment made points to the fact that "post-sheltering, decreasing amounts of sea salt aerosol concentrations were found, notwithstanding that the outside prevailing wind speeds were higher" (p. 324).

From these results, the conclusions by Galea et al. are as follows: "This important result indicates that higher wind speeds alone at Hagar Qim which are transporting sea salt aerosols inside the temple, may not be the most significant factor affecting greater deposition of sea salt aerosol under the sheltered temple. On the other hand, low wind speed and higher turbulence favour greater soil dust

\footnotetext{
${ }^{30}$ In February, late February to early March, and December 2009 - both pre- and post-sheltering. It must be noted however that sampling was carried out in different locations each time. It is not known why different apses were monitored in different campaigns.
} 
deposition (unpublished report: Gomez-Bolea et al. ${ }^{31}$ ). While buoyancy of sea salt aerosol alone may be different to soil dust and other windborne dusts such as Sahara dust, the major problem which would be common to both deposition sources is the accumulation on the limestone surface over time. Therefore, further consideration of other pollution deposition that poses a threat to the already porous deteriorated limestone megaliths, such as dust deposits which carry potentially and equally dangerous soluble fractions, should also be considered as the two are intrinsically tied." (p. 324) (our italics). This "accumulation" of salts on the aerosol samplers (at least) however was not detected in their albeit short and limited sampling campaign and analyses, except for phosphates (19.8 ppm in a sheltered situation compared to 1.97 and $2.23 \mathrm{ppm}$ in unsheltered situations) - but not for the more damaging chlorides and sulfates. In fact the concentrations are lower for chlorides ${ }^{32}$ in the third (sheltered) campaign (38.59 ppm sheltered compared with 50.16 and $49.95 \mathrm{ppm}$ in unsheltered situations), and in the case of sulfates only marginally more $(9.94 \mathrm{ppm})$ in the sheltered situation than those measured in the first (unsheltered) campaign $(9.75 \mathrm{ppm})$ and markedly less than in the second (exposed) campaign $14.30 \mathrm{ppm}$ ). It is also worth again mentioning here that a massive increase in soluble ions was in fact registered between 1985 and 2005, when the Temples were still unsheltered, discounting the comments often made, but not substantiated, that rainwater simply "washes away" soluble salts from the stone surface, and that, therefore, a shelter will "necessarily" lead to greater salt accumulation.

In addition, it is here worth mentioning that for many years there has been a yearly campaign of spraying glyphosate (Roundup ${ }^{\circledR}$ ) in the vicinity of the Temples to control herbaceous growth. Spraying in fact took place in December 2009. It is known that the half-life of glyphosate ranges from a few days up to a year (depending on soil composition) [20] and is known to degrade to phosphate in soil. ${ }^{33}$ This could therefore have contributed at least in part to the high phosphate levels detected under the shelter in the third campaign which took place in that

\footnotetext{
${ }^{31}$ A. Gómez-Bolea et al., Universitat de Barcelona, Environmental Monitoring at Hagar Qim and Mnajdra Temples: Final Report, 2008 (unpublished report).

32 Again we are in different sample locations and with different environmental (wind) conditions.

${ }^{33}$ Glyphosate is degraded into phosphate in soil according to several studies. Forlani http://citeseerx.ist.psu.edu/viewdoc/download?doi=10.1.1.89 $5.9892 \&$ rep $=$ rep1\&type $=$ pdf attributes the degradation of glyphosate into phosphate to bacteria in the soil. Monsanto, the company who developed Roundup, says it degrades to phosphate, https:/monsanto.com/app/uploa ds/2017/06/gly_phos_bkg.pdf. The Environmental Monitoring \& Pest Management Department of Pesticide Regulation Sacramento, CA also lists phosphate as one of the end products of the degradation of glyphosate in soil http://www.cdpr.ca.gov/docs/.
}

same month, if this had affected and accumulated on the sample filters. This is particularly significant since most of the conclusions drawn by these researchers on increased pollutant accumulation relate to the "phosphate value deposition result in third campaign" [18] p. 324 which was from 3 December to 17 December 2009.

An unrelated but also potentially negative effect is the fact that the presence of the shelters, and especially the insertion of complex metal trusses which support the membrane over the Temple sites, seems to have increased the Spanish Sparrow's nesting in the non-urban sites of Hagar Qim and Mnajdra. It has been observed that the modified behaviour of the birds, including a possible lengthening of the breeding season, has led to an increase in the presence of bird droppings on some of the megaliths [8]. These can be deleterious to the stones, and therefore need to be immediately removed.

\section{General conclusions on impacts of shelters}

These can be summarised as follows ${ }^{34}$ :

1. Air $\mathrm{T}$ and $\mathrm{RH}$ fluctuations have been mitigated, especially in the centre of the shelter; $\mathrm{RH}$ values are still very high.

2. The microclimate being more stable, together with the resulting shading effect, are probably resulting in a reduced risk of overall weathering inside the shelter.

3. The elimination of ponding inside the Temples contributes to a great reduction in rising damp, and hence can also mitigate against salt weathering problems.

4. Predictions on $\mathrm{NaCl}$ crystallisation events, based on environmental data, are however not consistent over the two evaluated years.

5. Wind speed has been reduced for the most part inside the shelter; however there is resulting dust accumulation, which can in part be attributed to the drying of the soil inside the shelter and possibly also to the influx of soil particles from the surrounding arid environment.

6. For biological cover, changes in lichen cover registered so far have been negligible, while there has been an appreciable reduction in the growth of higher plants.

In all cases, longer monitoring needs to be carried out.

\section{Lessons learnt}

One general lesson that has been learnt since the completion of the shelters concerns residual effects of the situation before sheltering. While some factors, such as

\footnotetext{
${ }^{34}$ Much less data evaluation has taken place in the case of monitoring at the Tarxien shelter, and therefore this shelter has not been considered in the section of the paper.
} 
insolation or direct rainfall, allow a direct comparison of the pre-shelter situation to that prevailing immediately after sheltering (if monitoring is comprehensive and sustained), this is not the case with some other variables, including the slow drying out of the ground, infill and the megalithic stones themselves. A transitional stage will always occur, of which it is impossible to determine the duration beforehand, and will vary on a site-by-site basis, and which may affect monitoring data; this can hence possibly skew any conclusions drawn in the short-term. One possible consequence of this in this case was the brief appearance of the green hue, possibly biological in composition, on a few megaliths inside Mnajdra Temples, already mentioned. Other unexpected scenarios may occur in different sites and different locations.

A related lesson learnt is that the number and variety of parameters to be monitored need to be determined a priori and can only be based in part on known, or assumed, agents of deterioration in each specific case. There is no "one size fits all", although there are good guidelines to follow (e.g. [19]). Where and what to monitor, how long to monitor, and the frequency of monitoring ${ }^{35}$ are crucial in facilitating the evaluation process to follow but can only be established with innate imprecision beforehand; fine-tuning of the exercise as the study progresses may seem laudable-however, changing, or increasing parameters as the situation evolves will result in the accumulation of data which are only partial, and no firm base-line is ever established to compare later data with. Nonetheless there will be cases where hindsight shows that important parameters have not been measured, or else not measured adequately. In the case of the Maltese Temples, groundwater data, before and after, and inside and outside the sites themselves, could have helped contribute to a better explanation of the mechanisms of the documented weathering effects, both before and after sheltering. Surface moisture data, notoriously difficult to capture, would have given better indication of condensation episodes on the megalithic structures themselvesalthough surface wetness data captured by experimental sensors (unpublished report: Mandrioli et al. ${ }^{7}$ ) is useful in this respect. More information on wind and turbulence inside the different apses, both before and after sheltering, as well as surface deposition of dust and saltladen marine aerosols, could have helped to clarify current unknowns related to dust and aerosol deposition and their removal. ${ }^{36}$

Time and resources-financial and human-will always be limiting factors. As a result of this experience, it can

\footnotetext{
35 The choice of equipment to use is also crucial.

36 One unanswered question is-how correct is it to say that "rain washing" eliminated most of the surface salts? This is also a question these monitoring campaigns are attempting to answer.
}

however be stated that, as a rule of thumb, it is preferable to collect data for as many relevant variables as possible-it is however debateable how best to determine "relevance" in each specific case. However, it can be stated that relevant data include information pertaining to the atmosphere (air temperature, relative humidity, wind, insolation, aerosols) and also related to the ground and the structures themselves (water, salts, biological growth) - in well-chosen targeted areas which can have a good correlation with observed phenomena, and which are consistently monitored in the same way and the same locations. ${ }^{37}$ For environmental data, 1 year (four seasons) of monitoring is usually considered to be the absolute minimum to draw any realistic conclusions. Our experience shows that two or even 3 years are not sufficient-4 or more years would be preferable-so as to smooth out any anomalies that may occur in any particular year or years. This goes for both before and after sheltering. It is also essential that adequate time is set aside to process and compare the often very large datasets that result from such monitoring and compare them with site observations judiciously obtained and diligently recorded both before and after sheltering. The importance of regular condition assessments-not all need to be comprehensive or very detailed-cannot be overemphasized. Where insolation is a concern, thorough and continuous recording of surface temperatures, before and after sheltering, is crucial. Where frost is an issue, ${ }^{38}$ the number and occurrence of such events must be recorded. Aerosolsmarine, biological or other-may be crucial depending on the location of the site. ${ }^{39}$

A further lesson learnt during the experience of the sheltering projects under review was that, while there were very clear ideas and predictions regarding what the shelters were meant to achieve, especially in the longterm, only general performance indicators had been established prior to the sheltering. As data for the environmental behaviour of comparable shelters in similar climates were not available, it was difficult or impossible to establish more detailed indicators in advance, including numeric values. As more experience and data are accumulated from different sheltering projects, it should become more realistic to establish such numeric performance indicators and expectations at the outset of a project, with the advantage that it would make it much easier

\footnotetext{
37 The experience from the "pollution monitoring" paper shows that possibly incorrect conclusions can be derived by inconsistency in the sampling procedure.

38 Frost is not an issue in Malta.

39 If over-riding factors, including natural hazards (earthquakes and floods for example) are an important issue, it may be decided that a shelter could be a liability instead of a solution.
} 
to have an objective and factual discussion of whether those indicators have been achieved or surpassed.

The present paper has aimed at giving a summary of the events, studies and discussions that led to the installation of the shelters over three of the Maltese Megalithic Temple sites, as well as a scientific overview of the current understanding of their performance. One of the main purposes of doing so is to share some of the lessons learnt with colleagues responsible for the conservation and management of other vulnerable sites, where the possibility of a similar intervention is being considered. Some key guiding principles which can be considered useful are outlined below.

\section{To shelter or not to shelter?}

It must be clearly remembered that each site presents its own unique conservation challenges. The discussion on whether a shelter may be desirable, always as part of a wider conservation strategy for a given site, will depend greatly on:

1. structure and extent of the remains

2. location, surrounding terrain, climate and specific environmental conditions

3. materials making up the site

4. particular deterioration mechanisms and their causes

5. scale and gravity of the conservation problems

6. resources available.

It must also be kept firmly in mind that a shelter may not be the solution to identified problems. In addition, if it is decided to shelter, it must be remembered that a shelter can only perform well as part of a holistic conservation strategy that needs to be clearly thought through before any decision is taken, and which addresses questions such as: what short-term and long-term measures need to be put in place; what conservation (including monitoring) programme will be required before and after sheltering; what sort of shelter is needed; how can the chosen shelter affect parameters, not only individually, but also how they act in synergy; what is the lifetime of the chosen shelter; what risks may sheltering pose to the site, during and after construction, and eventually, during dismantling; under which circumstances would the shelter be removed; if so, with what can/will it be replaced. Site considerations, including how any shelter will affect aesthetics and context, must also be seriously debated with all stakeholders before any decision is taken. ${ }^{40}$

Any decision to shelter should thus be based on a thorough understanding first of the site itself and its state of

40 This has not been discussed in the paper, as it is not within the scope of the paper, but has been addressed in other papers $[9,10])$. conservation, as well as a good idea of the possible causes of any problems identified [21]. The interactions of different agents that may be contributing to the deterioration of the specific site, and how sheltering is expected to improve the situation, as well as any other effects that it may have, must be clearly outlined (as far as possible) and must be discussed on a multi-disciplinary platform, with specialists who can contribute to the final decision.

It is also imperative to first identify and then collect reliable and continuous data on the identified key environmental and material- and structure-related factors, and other relevant issues as explained in this paper, before, during and after sheltering, and to maintain an open discussion at every stage, including with all players in the process. This is especially needed in case the monitoring programme may need to be expanded, refined or rethought, ${ }^{41}$ as well as when evaluating the implications of the collected data, and conclusions drawn, for the conservation of the site. Impacts of sheltering "are more complex than might have been expected" [14], p. 11 and therefore continued studies, both before and after sheltering, are crucial to long-term success. Each and every shelter put in place will have a definite lifetime-25 years in our case. It is therefore crucial that data are collected at all stages of the sheltering process, including before any shelter is put in place, in order to inform any subsequent decision taken on whether to replace the first shelter with an identical one, a different one, or indeed possibly none at all. Hence the importance of having a wide spectrum of monitoring data.

\section{Future research agenda}

So far, inferences about salt weathering based on data for specific contributing factors, such as ambient $\mathrm{RH}$ and air temperature, can be suggested, but only with great caution. ${ }^{42}$ In this light, Becherini et al. [8], p. 9 note the need for "...longer-term studies on the Temples [that] will eventually lead to a closer correlation being identified between measured data, types of measurement and stone deterioration forms observed and mapped." This work also needs to include regular, detailed and repeated condition assessments. Modelling of salt behaviour, given the existing data, is planned and should go a long way to understanding, and predicting, real salt damage, as has already been discussed by others [22].

The understanding obtained to date regarding the fluctuations of ambient RH below the shelters thus needs to be complemented by evidence-based modelling of salt cycles, which also takes into account the interaction with

\footnotetext{
${ }^{41}$ A note on the possible inadvisability of changing parameters mid-stream has already been given.

42 In addition, the synergy with pollutants in the air, and in the stone, must also be investigated.
} 
other factors, such as temperature fluctuations in the air and on the surface and within the stone, hygroscopicity and deliquescence, as well as the duration of each theoretical 'cycle' of ambient RH across a crystallization/dissolution threshold. And the presence of salt mixtures rather than single salts [23]. This of course will not be simple or immediate, but is feasible.

A related challenge is that direct measurement of the rates of material loss on the prehistoric surfaces is notoriously difficult. High-resolution laser-scanning of surfaces has been successfully applied to document erosion processes in other contexts [24], and other methodologies have also been used, including a combination of methods [25]. A long-term programme of such monitoring is a desideratum here. This information will support the observations made and recorded during the condition assessments, as well as support all the indirect evidence obtained regarding the effectiveness of a sheltering project, as discussed above.

Another consideration for a future research agenda is not strictly tied to sheltering itself. This is the challenge of seismic vulnerability. The structural stability of the megalithic structures has been severely compromised by the cumulative loss of fill material and erosion of architectural components. The monuments remain extremely vulnerable, and would probably suffer catastrophic damage if an even moderate earthquake were to occur in the vicinity. The study and design of possible measures to manage this risk must remain a high priority on the research agenda. As already mentioned, where other natural hazards are present (e.g. floods, hurricanes) dedicated research agendas must address the risks involved and possible mitigation strategies.

\section{Final comments}

The general consensus is that, for Malta, "the investigations carried out so far indicate that the shelters seem to be an appropriate solution" [8], p. 10. Thus, it can be concluded that these shelters are effective and, especially in the case of Hagar Qim, the most thoroughly studied site by far, "the site would be exposed to more damaging conditions if it was not sheltered" [13], p, 702. However, it must also be concluded that monitoring for limited periods, even up to two years, is not sufficient and "investigations over longer time spans are recommended" [14], p. 11. We suggest here a minimum of 4 years before, and 4 years after sheltering, but it will vary on a case-by-case basis. Monitoring vulnerable sites, not only where sheltering can be a possibility, is part of best-practice geared towards their preservation. Such data will not only help assess any problems or changes in the state of conservation of the site, but will provide important base-line information for any sheltering that may be considered. Condition assessments, on a regular basis, are also essential. These should also be routinely carried out.

One final consideration is in relation to climate change. This is one of the greatest modern challenges which also directly affects our historical buildings and archaeological heritage [26-30]. Studies of the impacts of climate change on heritage are limited-those impacting a sheltered site are even less known. Studies should commence without delay to understand the possible long-term implications both exposed and covered sites, if their long-term preservation is a desideratum.

\section{Authors' contributions \\ The authors have all made fundamental contributions to this paper, with the main writing of the collated information being done by JC. SC, RG and KS have provided most of the background information, contributed to the writing of the review, evaluation of unpublished and published results, discussion of the data and the lay-out of the paper. Figures were provided by KS. All authors read and approved the final manuscript.}

\section{Author details}

${ }^{1}$ Department of Conservation and Built Heritage, Faculty for the Built Environment, University of Malta, Msida MSD2080, Malta. ${ }^{2}$ Prehistoric Sites Department - Heritage Malta, Tarxien Temples, Neolithic Temples Street, Tarxien TXN1062, Malta.

\section{Acknowledgements}

This paper has been written by the four declared author. The authors wish to acknowledge Dr. Josef Caruana, Curator Prehistoric Sites, Heritage Malta, for his insight and research into the effects of glyphosate on salt monitoring at these sites. Dr. Francesca Becherini. Researcher at the Institute of Atmospheric Sciences and Climate of the National Research Council Italy, is thanked for her contribution on the further statistical analysis of direct surface temperature data already reported in a paper in which she was lead author. All authors of published papers and unpublished reports are declared in References and Endnotes. ERDF funding for the studies and construction of the shelters is gratefully acknowledged (as mentioned in "Funding").

\section{Competing interests}

The authors declare that they have no competing interests.

\section{Availability of data and materials}

Three of the fundamental unpublished reports which have provided some of the key information reviewed in this paper are available in the figshare repository [https://doi.org/10.6084/m9.figshare.5995453.v1] [https://figsh are.com/articles/Malta_Temple_Sheltering_Unpublished_reports_Biological _and_Environmental_surveys/5995453\}.

\section{Ethics approval and consent to participate} Not applicable.

\section{Funding}

The various funding bodies have already been included in the article. The construction of the Haġar Qim and Mnajdra shelters was co-funded by the EU through the ERDF 2004-2006 Structural Funds Programme. That over the Tarxien Temples was co-funded through the ERDF 2007-2013 Cohesion Policy.

\section{Publisher's Note}

Springer Nature remains neutral with regard to jurisdictional claims in published maps and institutional affiliations.

Received: 8 December 2017 Accepted: 29 May 2018

Published online: 11 June 2018 


\section{References}

1. Galdies C. The climate of Malta: statistics, trends and analysis 1951-2010. Malta: National Statistics Office; 2011. https://nso.gov.mt/en/publicaton s/Publications_by_Unit/Documents/B3_Environment_Energy_Trans port_Agriculture_Statistics/The_Climate_of_Malta.pdf. Accessed 16 Mar 2018.

2. Cassar J, Tampone G, Vannucci S. Conservazione e Restauro dei Templi Megalitici Preistorici Maltesi: il progetto bilaterale di ricerca e risultanze delle prime missioni di studio. In: Zezza F, editor. Conservation of monuments in the Mediterranean Basin. Proceedings of the 1st international symposium, Bari, 1989. Brescia: Grafo; 1989. p. 139-46.

3. Tampone G, Vannucci S, Cassar J, Giordano S, Fiorito S, Pieri-Nerli P, Sausa P, Zetti I. Templi Megalitici Preistorici delle Isole Maltesi: determinazione delle propieta' meccaniche dei materiali ed interpretazione dei dissesti. In: Fassina V, Ott H, Zezza F, editors. Conservation of monuments in the Mediterranean Basin. Proceedings of the 3rd international symposium. Venice: Soprintendenza ai Beni Artistici e Storici di Venezia; 1994. p. 567-75.

4. Cassar J, Vannucci S. Petrographical and chemical research on the stone of the megalithic temples. Malta Arch Rev. 2001;5:40-5.

5. Vannucci S, Alessandrini G, Cassar J, Tampone G, Vannucci ML. I Templi Megalitici Preistorici delle Isole Maltesi: cause e processi di degradazione del Globigerina Limestone. In: Fassina V, Ott H, Zezza F, editors. Conservation of monuments in the Mediterranean Basin. Proceedings of the 3rd international symposium. Venice: Soprintendenza ai Beni Artistici e Storici di Venezia; 1994. p. 555-65.

6. Rothert E, Eggers T, Cassar J, Ruedrich J, Fitzner B, Siegesmund S. Stone properties and weathering induced by salt crystallization of Maltese Globigerina Limestone. In Prikryl R, Smith BJ, editors. Building stone decay: from diagnosis to conservation. Special Publications 271. London: The Geological Society of London. 2007. p. 189-98; https://doi.org/10.1144/ gsl.sp.2007.271.01.30.

7. Torpiano A. The collapse and proposed restoration of a prehistoric megalithic structure. Trans Built Environ 1995;15:237-244. https://www.witpr ess.com/Secure/elibrary/papers/STR95/STR95027FU2.pdf. Accessed 16 Mar 2018.

8. Becherini F, Cassar J, Galea M, Bernardi A. Evaluation of the shelters over the prehistoric Megalithic Temples of Malta: environmental considerations. Environ Earth Sci. 2016;75(14):1-13. https://doi.org/10.1007/s1266 5-016-5875-z.

9. Cassar J, Galea M, Grima R, Stroud K, Torpiano A. Shelters over the Megalithic Temples of Malta: debate, design and implementation. Environ Earth Sci. 2011;63:1849-60. https://doi.org/10.1007/s12665-010-0735-8.

10. Grima R, Stroud K, Torpiano A. The protective shelters at Haġar Qim and Mnajdra: impacts, dilemmas and values. In: Borg RP, editor. Challenges in conservation of architectural heritage. Malta: Kamra tal-Periti. 2011. p. 3-14; https://doi.org/10.13140/2.1.1985.2165.

11. Farrugia S, Schembri JA. Wind funneling underneath the Hagar Qim protective shelter. Malta Arch Rev. 2008-2009;9:51-9.

12. Bonazza A, Sabbioni C, Messina P, Guaraldi C, De Nuntiis P. Climate change impact: mapping thermal stress on Carrara marble in Europe. Sci Total Environ. 2009; 407:4506-12

13. Cabello-Briones C, Viles HA. Is the shelter at Hagar Qim in Malta effective at protecting the limestone remains? In: Hughes J, Howind T, editors. Science and art: a future for stone: proceedings of the 13th international congress on the deterioration and conservation of stone. Paisley: University of West Scotland; 2016. p. 695-702.

14. Cabello-Briones C, Viles HA. Evaluating the effects of open shelters on limestone deterioration at archaeological sites in different climatic locations. Int J Arch Herit. 2017. https://doi.org/10.1080/15583058.2017.13007 10

15. Cassar J. Past stone restoration methods in the Maltese islands. In: Daniels V. Editor. Early advances in conservation. Occasional paper no. 65. London: British Museum; 1988. p. 103-30.

16. Chen J, Blume H, Beyer L. Weathering of rocks induced by lichen colonization: a review. CATENA. 2000:39:121-46.

17. Llop E, Alvaro I, Hernandez Marine M, Sammut S, Gómez Bolea A. Biological crusts contribute to the protection of Neolithic Heritage in the Mediterranean region. In: Rogerio-Candelera MA, Lazzari M, Cano E, editors. Science and technology for the conservation of cultural heritage. London: Taylor and Francis Group; 2013. p. 33-6.
18. Galea M, DeBattista R, Grima M, Maccarelli L, Borg R, Zerafa C. Pollution monitoring for sea salt aerosols and other anionic species at Hagar Qim Temples, Malta: a pilot study. Conserv Manag Arch Sites. 2015;17:315-26. https://doi.org/10.1080/13505033.2016.1191890.

19. Camuffo D. Microclimate for cultural heritage. 1st ed. San Diego: Elsevier; 1998.

20. Székács A, Darvas B. Forty years with glyphosate. In: Naguib Abd El-Ghany Hasaneen M, editor. Herbicides: properties, synthesis and control of weeds. Rijeka: InTech; 2012. https://doi.org/10.5772/32491.

21. Rafiee Fanood $M$. The debate on the need for a protective shelter over the Mausoleum of Cyrus the great. J Arch Conserv. 2014;18(3):53-70. https://doi.org/10.1080/13556207.2012.10785118.

22. Flatt RJ, Aly N, Caruso F, Derluyn H, Desarnaud J, Lubelli B, Espinosa-Marzal RM, Pel L, Rodriguez-Navarro C, Scherer GW, Shahidzadeh N, Steiger M. Predicting salt damage in practice: a theoretical insight into laboratory tests. RILEM Tech Lett. 2017;2:108-18. https://doi.org/10.21809/rilemtechl ett.2017.41.

23. Franzen C, Mirwald PW. Moisture sorption behaviour of salt mixtures in porous stone. Chem Erde. 2009;69:91-8.

24. Smith BJ, Gomez-Heras M, Meneely J, McCabe S, Viles HA. High resolution monitoring of surface morphological change of building limestones in response to simulated salt weathering. In: Lukaszewicz JW, Niemcewicz P, editors. 11 th international congress on deterioration and conservation of stone (2 volumes). Torun: Wydawnictwo Naukowe Universytetu Mikolaja Kopernika; 2008. p. 275-82.

25. Andre MF, Phalip B. Rates of stone recession on Mediaeval monuments: some thoughts and methodological perspectives. Cadernos Lab Xeoloxico de Laxe Coruna. 2010;35:13-40.

26. Viles HA. Implications of future climate change for stone deterioration. Geol Soc Lond Spec Pub. 2002;205:407-18. https://doi.org/10.1144/GSL. SP.2002.205.01.29.

27. Chitty G. Meeting the climate change challenge-at the next IFA conference. The Archaeologist. 2007;66:16-17. https://www.archaeologists.net/ sites/default/files/ta66.pdf. Accessed 16 Mar 2018.

28. Sabbioni C, Brimblecombe P, Cassar M. The atlas of climate change impacts on European cultural heritage: scientific analysis and management strategies. London: Anthem Press; 2010.

29. Daly C. Climate change and archaeological sites; a review of impacts theory. Conserv Manag Arch Sites. 2012-2013;4:293-310. https://doi. org/10.1179/175355212×13315728646058.

30. Cassar J. Climate change and archaeological sites: adaptation strategies. In: Lefèvre RA, Sabbioni C, editors. Cultural heritage from pollution to climate change. Santo Spirito (Bari): Edipuglia; 2016. p. 119-27.

\section{Submit your manuscript to a SpringerOpen ${ }^{\circ}$ journal and benefit from:}

- Convenient online submission

- Rigorous peer review

- Open access: articles freely available online

- High visibility within the field

Retaining the copyright to your article

Submit your next manuscript at $>$ springeropen.com 